\title{
COMPARATIVE STUDY OF ONE AND TWO DIODE MODEL OF SOLAR PHOTOVOLTAIC CELL
}

\author{
Ritesh Dash ${ }^{1}$, S.M Ali ${ }^{2}$ \\ ${ }^{I} P G$ Scholar, School of Electrical Engineering, KIIT University \\ ${ }^{2}$ Asso.Prof. School of Electrical Engineering, KIIT University
}

\begin{abstract}
Modeling of solar cell is a very difficult task. This is because of the non linear behavior of the cell. Different types of modeling for solar cells are available in the literature. The theme of the modeling is based on the solar radiation and temperature of the system and environment. Determination of cell parameters like Iph, Is, Rs ,Rsh and ideality factor generally affects the performance of the solar cell. This paper will basically describe about the one diode model of the solar cell. The initial parameter are evaluated by generating some random number through a computer program and from the manufacturer data sheet provided by the manufacturer. The result of the simulation will describe about the performance of two types of model.
\end{abstract}

Keywords: Solar PV, One diode model, Two diode model

\section{INTRODUCTION}

Shortage of energy drives us to think for some alternate source of energy. Major portion of energy is usually extracted from the coal. But from estimation it was found that the amount of coal available will last for another 30 years. So in this regard harvesting energy from renewable sources is the only option to adopt. Among the different renewable sources solar photovoltaic is the leading area of research. Now days, solar photovoltaic finds its wide applications in grid connected system as well as off grid applications. This is because of its availability and easy to handle and installation. By keeping view on the rapid growth of the solar industry it seems to be the largest source of energy producer in the future. Solar photovoltaic performance depends upon a number of parameters like altitude, humidity, temperature, solar radiation, shadow, azimuthal angle, tilt angle and the amount of load connected to the system. Solar cells are generally connected in series and parallel connection to increase the rating of the system and hence increase the efficiency. Despite of all the effort made to increase the efficiency of the solar cell the maximum achievable efficiency is only 30 percent and having maximum life span of 25 years. Another major cause of lower efficiency is the non linear behavior of the output, which again depends upon solar radiation. Efficiency of the solar cell can be increased to a markup value through proper design and modeling of the cell. Modeling of the cell depends upon the initial assumption for the system and as well as the type of the material. The modeling should satisfy the exact characteristic of the practical solar cell. Again run time of the model should be reasonable and under control.

Different types of modeling are available like artificial neural network, particle swarm model, loop control algorithm and many more. All these methods have some advantages as well as disadvantages. Artificial neural network and particle swarm optimization are not suitable because lots of data are required to process and test the model. Similarly particle swarm optimization use a number of data to simulate the system. With increase in parameter, PSO becomes lengthy and time consuming. Another point can be made like in ANN training at each node is required. Further more training requires lots of experiment to train the node and a regular updating of the node is a time consuming operation. On the other hand lumped parameter analysis is quite easy and also efficient one. Different types of lumped parameter model are their like one diode model, two diode model. The main problem with this type of model is that prior to the simulation it is required to solve a number of equations to find the first initial condition. One diode model assumes only two parameter i.e. solar radiation and temperature. However this method neglects the recombination losses i.e. occurring inside the cell due to charge carriers. Therefore the maximum efficiency will occur only in the varying temperature condition. Similarly under low irradiance condition its accuracy cannot be determined with one diode model. Therefore two diode model was developed. The model also suffers from some problem like it assumes Rsh and Rse before calculating the modeling parameter.

This paper will describe about different types of modeling of solar cell with their detailed mathematical derivation. The last part of the paper will describe about the comparison between different types of modeling.

\section{MODELING OF SOLAR CELL}

Different methods of modeling were described in the literature. Ref[2] has proposed a model based on particle swarm optimization method with its derived parameter from hybrid model. Similarly Ref.[3] described about the modeling of solar cell using matlab simulink model. .However both the method has assumed a lots of parameter 
like coefficient, $\mathrm{Ki}, \mathrm{Kv}$ which not only increase the number of equations but also increases the computation time.

Wolf has proposed a solar cell consisting of a current source, diode and resistor. Latter on wolf modeling has been simplified to one diode model system. From the one diode model of solar cell, the total photogene generated current (Iph) can be written as

$$
I p h=\left(\frac{G}{G s t c}\right)\left\{I_{p h} s t c+k i(T-T s t c)\right\}--------
$$

Where $\mathrm{g}$ is the solar radiation, Gstc is the solar radiation under standard temperature condition, $\mathrm{ki}$ is the current coefficient, $t$ is the temperature and tstc is the temperature under stc. Similarly the total output current from the solar cell can be found from -2 as

$$
\text { I=Iph-Id-Ir---------- }
$$

Where I is the net output current of the solar cell Iph is the net photo generated current from the solar cell, Id is the diode current flowing through the diode and ir is the current through the resistor. Expanding the current equation with its internal parameter it becomes

$$
I=I p h-I\left\{\exp q\left(\frac{V+I A g}{n h T}\right)-1\right\}-\left(\frac{V+I A g}{\pi g h}\right)-
$$

Where $\mathrm{T}$ is the temperature of the solar cell under solar irradiance and $\mathrm{n}$ is the ideality factor of the solar cell. These equations are quite suitable for for simulating the solar cell under different constraints. But one of the draw back with this type of simulation is that it is not suitable under low irradiance condition. Under this condition the net photo generation from the solar cell behaves like an open circuit condition. So under open circuit condition the equation fails to describe about the recombination process or recombination losses occurring in the solar cell. Under varying temperature condition it exhibits non linear dynamic equation where it is difficult to study the characteristics of solar cell. the above problem associated with the one diode model can be eliminated with two diode model . However the number of equations to be solved for two diode model is much more as well as tedious to describe. The problem associated with two diode model simulation is that the run time for simulation. Thevenin modelling of solar cell is applied to calculate the parameters. Series and shunt resistance are included to calculate the performance. Levenberg function is applied finally on the output result to study the curve of solar cell. The equation introduced under this method has a lots of parameter. So iteration method is applied to find the parameters. The iteration method has a lots of assumption like initial condition, step size for iteration and result testing. Choosing the initial condition is a difficult task. The output of the solar cell is very sensitive to the initial parameter of the solar cell. The two diode model of the solar cell has two different method like small signal analysis and large signal model analysis. The small signal model consist of only five numbers of parameter where as large signal analysis consist of seven parameter model . The initial value for five parameter model consist of series and shunt resistance where as for seven parameter analysis only series resistance is required. It is better to choose one variable rather than two variable. So this paper will describe the basic equations of different model and an iterative technique to find the solution.

\section{METHODOLOGY}

From figure-1 the equation for one diode model becomes

$$
I=I p h-I s\left(\exp q\left(\frac{V+I R g}{\operatorname{miVt}}\right)-1\right)-\frac{V+I A g}{\operatorname{Rgh}}
$$

and from figure- 2 the equation for the equation for two diode model becomes

$$
\begin{aligned}
& I=I p h-I s 1\left(\operatorname{expq}\left(\frac{V+I A g}{n 1 V t}\right)-1\right)-I s 2\left(\exp q\left(\frac{V+I A g}{m 1 V t}\right)-\right. \\
& 1)-\frac{V+I A g}{R g h}
\end{aligned}
$$

The difference between the two modelling equation is the introduction of saturation current . The two diode model Consist of two saturation current i.e. Is1 and Is2.The two diode model represents the recombination losses occurring in the junction of solar cell. If $\mathrm{Np}$ is the number of cells connected in parallel and Ns is the number of cells connected in series then the current equation becomes

$$
\begin{aligned}
& l= \\
& I p h-I s 1 N p\left(\exp q\left(\frac{V+I R g}{\text { MIVt }}\right)-1\right) \operatorname{Is} 2 N p\left(\exp q\left(\frac{V+I R g}{\text { naVt }}\right)-\right. \\
& \text { 1) }-\frac{\text { Wa }(\mathrm{V}+\mathrm{IRa})}{\text { Wpish }}
\end{aligned}
$$

The photo generated current Iph can be found out as follows

$$
I p h=\left(\frac{s}{s e t}\right)\left\{I p h_{v} s t c+K i(T-T s t c)\right\}-------
$$

Similarly the saturation current can be written as

$$
I s 1=I s 1_{v} \operatorname{stc}\left(\frac{T}{T u t e}\right)^{\mathrm{a}} \exp \left[\left(\frac{q E g}{\mathrm{M} 1 \mathrm{R}}\right)\left(\frac{1}{T \text { ste }}-\frac{1}{T}\right)\right]
$$

and that of

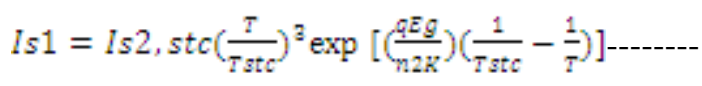

Here Is 1 and Is 2 depends on the temperature and irradiance Is 1 and Is 2 can be found out from the Newton's iterative method. According to Newton's iterative method the parameters at short circuit current and open circuit voltage can be found out as

$$
I=I s 1\left\{\exp \left(\frac{\text { Moc }}{\text { nIVt }}\right)-1\right\}+I s 2\left\{\exp \left(\frac{\text { Voc }}{\text { nat }}\right)-1\right\}+\left(\frac{\text { Voc }}{\operatorname{ggh}}\right)--
$$


And

$$
\begin{aligned}
& I s c=I p h-I s 1\left\{\exp \left(\frac{\operatorname{scc} R g}{\text { n1Vt }}\right)-1\right\}-I s 2\left\{\exp \left(\frac{\text { ngcRg }}{\text { navt }}\right)-\right. \\
& \text { 1) }-\left(\frac{\sec A g}{\operatorname{sgh}}\right)
\end{aligned}
$$

In five and seven parameter analysis of solar cell, all the parameters have a very sensitive effect on the performance of the solar cell. Among all these parameters ideality factor have several effect on the performance of cell. It represents the movement of carriers across the junction of the solar cell. generally two types of movement are there like diffusion process and recombination process. if the movement is diffusion then ideality factor becomes one and for recombination process the ideality factor is two. Some of the paper also recommended to take it as 1.5 . So it can be calculated as

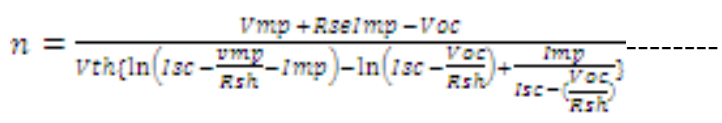

Where Vth represents thermally generated voltage, Vmp is the maximum voltage at the output curve, Imp is the maximum current at the output of MPP. $R_{\text {so }}$ and $R_{\text {sho }}$ represents series and shunt resistance of the cell respectively under open circuit condition. Actually this $\mathrm{R}_{\mathrm{so}}$ and $\mathrm{R}_{\text {sho }}$ acts as a balancing intermediate parameter between Rs and Rsh respectively. This reduces the open circuit voltage into as follows

$$
V o c=-n V \operatorname{thln}\left(\frac{N 0}{\mathrm{nVth}}(\text { Rso }- \text { Rs })\right)-------
$$

So Voc now depend on both Rso and Rs . A very small change in resistance selection affects the open circuit voltage. The ohmic loss of a solar cell is determined by the amount of series and shunt resistance. Series resistance represents the contact resistance of the system, base resistance and inter metallic resistance or

$$
\mathrm{R}_{\mathrm{se}}=\mathrm{R}_{\mathrm{b}}+\mathrm{R}_{1}+\mathrm{R}_{\mathrm{m}}
$$

\section{RESULT AND DISCUSSION}

Solar cell parameters were calculated numerically with the mathematical equations discussed above. The result of the model are listed in table-1. The PV characteristic is obtained under different solar radiation i.e. 800,900 and 1000 watt $/ \mathrm{m} 2$ respectively. For all the characteristic the ideality factor is one.

On analyzing the result, there is a very small change in Rse and photo generated current. However the reverse saturation current is more in the two diode model and less in one diode model.
Table-1 Comparision between mathematical and cell modeling

\begin{tabular}{|l|l|l|}
\hline Parameter & $\begin{array}{l}\text { Mathematical } \\
\text { Modelling }\end{array}$ & Cell Modelling \\
\hline Isc & 2.03 & 2.02 \\
\hline Voc & 85.5365 & 86.8 \\
\hline Im & 1.54 & 1.93 \\
\hline Vm & 67.78 & 70.4 \\
\hline
\end{tabular}

Table-2 Voc and Isc at different solar insolation

\begin{tabular}{|l|l|l|l|l|}
\hline $\begin{array}{l}\text { Paramete } \\
\text { r }\end{array}$ & $100 \mathrm{~W} / \mathrm{m}$ & $700 \mathrm{~W} / \mathrm{m}$ & $800 \mathrm{~W} / \mathrm{m}$ & $1000 \mathrm{~W} / \mathrm{m}$ \\
\hline Voc & 2 & 2 & 2 & 2 \\
\hline Isc & 75 & 84.3 & 84.92 & 85.5365 \\
\hline
\end{tabular}

Table 1 and 2 represents the simulation result of mathematical and cell modeling of solar cell. The result shows that error percentage between the mathematical and cell modeling is very close to each other and can be adopted for cell modeling.

Table-3 Comparison between one and two diode modeling

\begin{tabular}{|l|l|l|}
\hline Parameter & $\begin{array}{l}\text { One diode } \\
\text { modelling }\end{array}$ & $\begin{array}{l}\text { Two diode } \\
\text { modelling }\end{array}$ \\
\hline FF & 0.6011 & 0.7749 \\
\hline$\eta$ & 10.4374 & 13.5868 \\
\hline Rch & 44.01 & 36.47 \\
\hline Rch & 42.13 & 42.57 \\
\hline
\end{tabular}

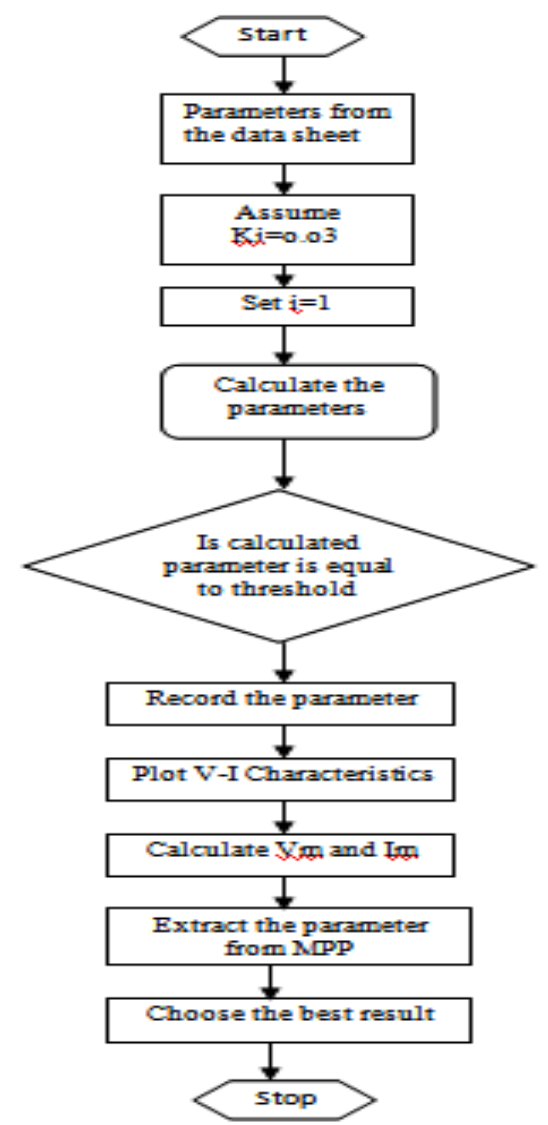

Fig: 1 Flow chart of the computer programming 
The entire computer program used to calculate the cell parameters are presented by a flow chart. on comparing different simulation result the best result was adopted for the simulation.

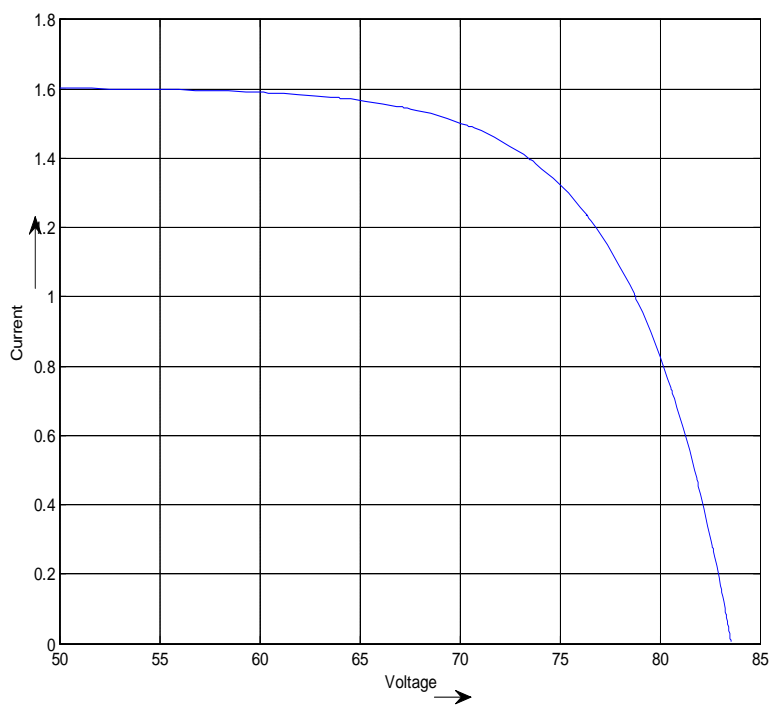

Fig: 2 V-I Characteristics under $800 \mathrm{~W} / \mathrm{m} 2$ radiation

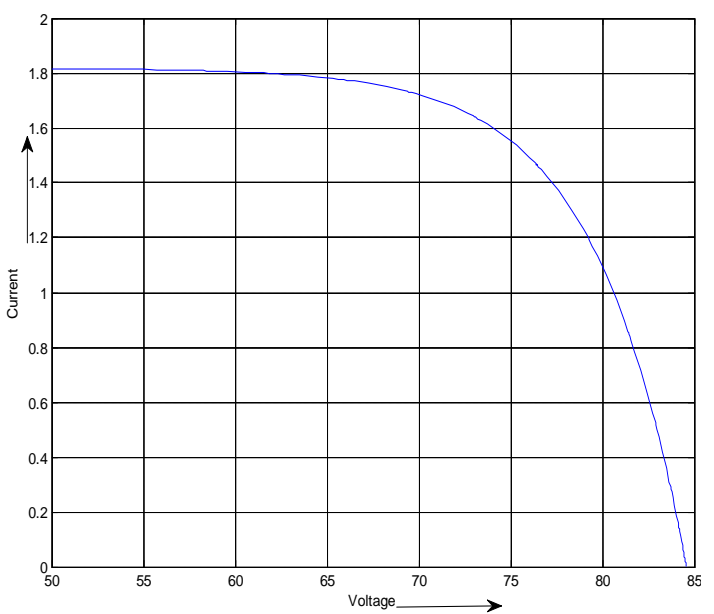

Fig: $3 \mathrm{~V}-\mathrm{I}$ Characteristics under $900 \mathrm{~W} / \mathrm{m} 2$ radiation

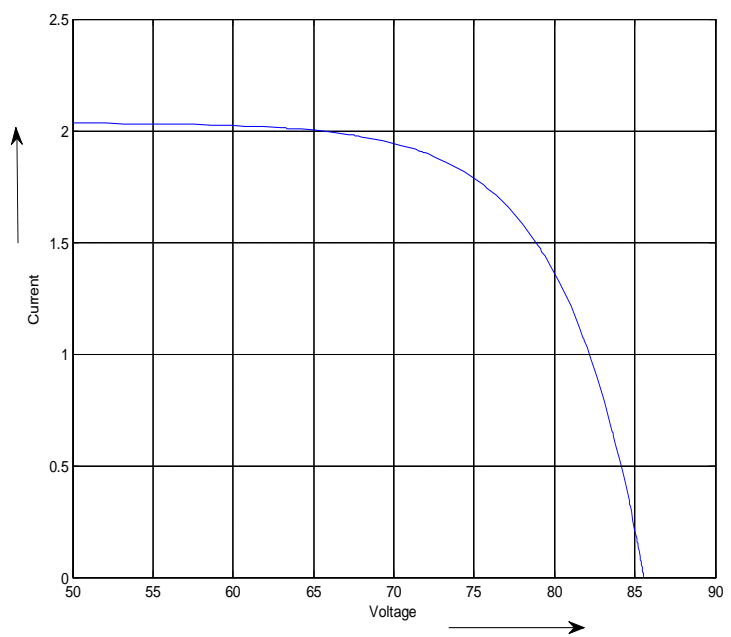

Fig: $4 \mathrm{~V}$-I Characteristics under $1000 \mathrm{~W} / \mathrm{m} 2$ radiation

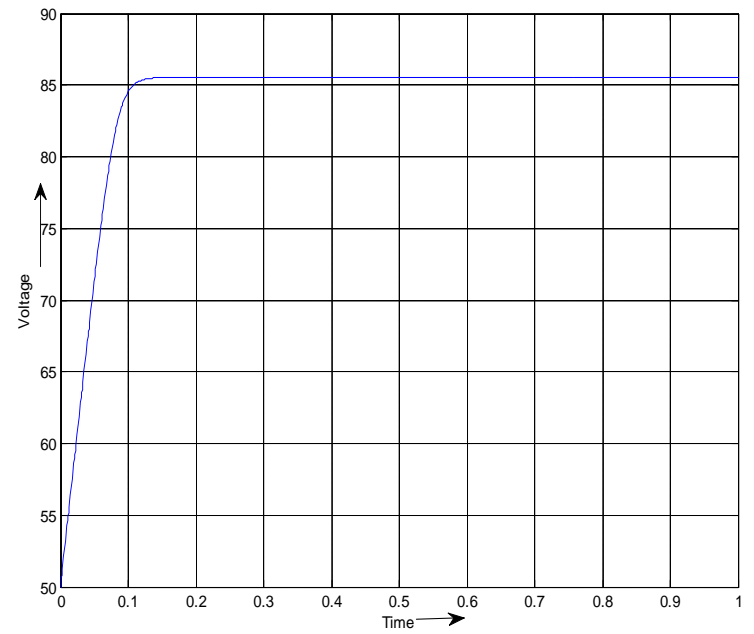

Fig: 5 Output Voltage curve for one diode model

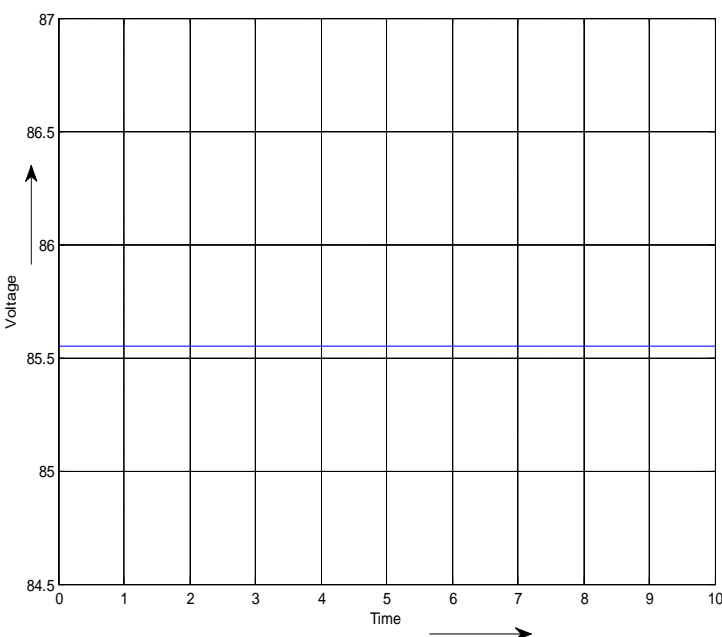

Fig: 6 Output Voltage curve for two diode model

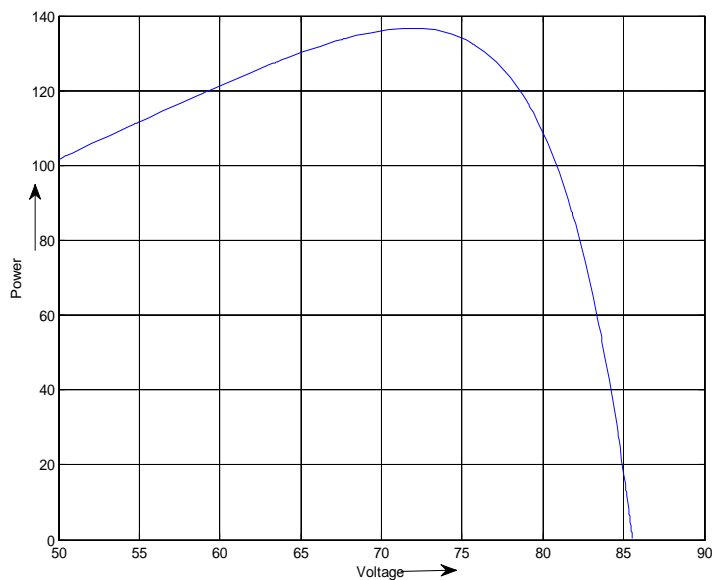

Fig: 7 P-V curve for one diode model

Figure 5 and 6 represents the output voltage of the one and two diode model of the solar cell with respect to time. The voltage for the two simulation was very much close to each other how ever the voltage profile of two diode model slightly small and the transient for the two diode model was also not there. This is because of the system loss in the series and shunt resistance. 


\section{CONCLUSION}

This work describes a new way of calculating the solar cell parameters. At first the numerical equations were solved to calculate the model for solar cell. The non linear equations involved in the modeling were represented by suitable block diagram in the matlab. The proposed method shown above can be used for calculating the parameters involved in the solar cell. The more précised analysis can be applied to real and practical system. The drawback involved in this type modeling is to solve a number of non linear equations. This in turn increases the execution time of the system.

\section{ACKNOWLEDGEMENTS}

We would like to thank the school of electrical engineering for providing us the necessary set up for successful completion of this research work.

\section{REFERENCE}

[1] F. Ghani, G. Rosengarten, M. Duke, J.K. Carson, The numerical calculation of single-diode solar-cell modelling parameters, Renewable Energy, Volume 72, December 2014, Pages 105-112, ISSN 09601481

[2] Otwin Breitenstein, An Alternative One-diode Model for Illuminated Solar Cells, Energy Procedia, Volume 55, 2014, Pages 30-37, ISSN 1876-6102

[3] F. Ghani, M. Duke, Numerical determination of parasitic resistances of a solar cell using the Lambert W-function, Solar Energy, Volume 85, Issue 9, September 2011, Pages 2386-2394, ISSN 0038-092X

[4] Wook Kim, Woojin Choi, A novel parameter extraction method for the one-diode solar cell model, Solar Energy, Volume 84, Issue 6, June 2010, Pages 1008-1019, ISSN 0038-092X

[5] Kashif Ishaque, Zainal Salam, Hamed Taheri, Amir Shamsudin, A critical evaluation of EA computational methods for Photovoltaic cell parameter extraction based on two diode model, Solar Energy, Volume 85, Issue 9, September 2011, Pages 1768-1779, ISSN 0038-092X

[6] M. Chegaar, G. Azzouzi, P. Mialhe, Simple parameter extraction method for illuminated solar cells, Solid-State Electronics, Volume 50, Issues 78, July-August 2006, Pages 1234-1237, ISSN 0038-1101

[7] Adelmo Ortiz-Conde, Francisco J. García Sánchez, Juan Muci, New method to extract the model parameters of solar cells from the explicit analytic solutions of their illuminated I-V characteristics, Solar Energy Materials and Solar Cells, Volume 90, Issue 3, 15 February 2006, Pages 352-361, ISSN 0927-0248

[8] W. De Soto, S.A. Klein, W.A. Beckman, Improvement and validation of a model for photovoltaic array performance, Solar Energy,
Volume 80, Issue 1, January 2006, Pages 78-88, ISSN 0038-092X

[9] M. Glatthaar, M. Riede, N. Keegan, K. SylvesterHvid, B. Zimmermann, M. Niggemann, A. Hinsch, A. Gombert, Efficiency limiting factors of organic bulk heterojunction solar cells identified by electrical impedance spectroscopy, Solar Energy Materials and Solar Cells, Volume 91, Issue 5, 6 March 2007, Pages 390-393, ISSN 0927-0248

[10] C. Carrero, J. Rodríguez, D. Ramírez, C. Platero, Simple estimation of PV modules loss resistances for low error modelling, Renewable Energy, Volume 35, Issue 5, May 2010, Pages 1103-1108, ISSN 0960-1481

[11] C. Carrero, D. Ramírez, J. Rodríguez, C.A. Platero, Accurate and fast convergence method for parameter estimation of PV generators based on three main points of the $\mathrm{I}-\mathrm{V}$ curve, Renewable Energy, Volume 36, Issue 11, November 2011, Pages 2972-2977, ISSN 0960-1481

[12] Hassan Fathabadi, Lambert W function-based technique for tracking the maximum power point of PV modules connected in various configurations, Renewable Energy, Volume 74, February 2015, Pages 214-226, ISSN 0960-1481

[13] Pankaj Yadav, Brijesh Tripathi, Kavita Pandey, Manoj Kumar, Effect of varying concentration and temperature on steady and dynamic parameters of low concentration photovoltaic energy system, International Journal of Electrical Power \& Energy Systems, Volume 61, October 2014, Pages 101110, ISSN 0142-0615

[14] ankaj Yadav, Brijesh Tripathi, Makarand Lokhande, Manoj Kumar, Estimation of steady state and dynamic parameters of low concentration photovoltaic system, Solar Energy Materials and Solar Cells, Volume 112, May 2013, Pages 65-72, ISSN 0927-0248

\section{BIOGRAPHIES}

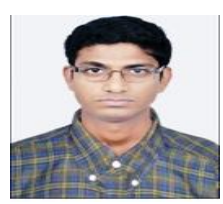

Ritesh Dash is a research scholar of power and energy system at KIIT university in the school of Electrical Engg. He has published more than 20 no. of papers both in journal and conferences. His research area includes Solar PV, Hybrid system, power system transient analysis.

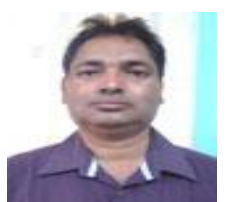

Dr S M Ali is Associate Professor in Electrical Engineering of KIIT University Bhubaneswar. He received his DSc \& $\mathrm{Ph} . \mathrm{D}$. in Electrical Engineering from International university, California, USA in $2008 \& 2006$ respectively. His area of research in the field of Renewable Energy both Solar \& Wind Energy. He has also presented more than 50 papers in different National \& International conferences in the field of Renewable Energy apart from around 20 nos of paper also published in National and International journals. 